\title{
ASO Author Reflections: The Theseus Paradox: Marked Lymph Node and Sentinel Lymph Node in pN+ Prechemotherapy Patients: Are They the Same?
}

\author{
Alejandra García-Novoa, MD, PhD (D), and Benigno Acea-Nebril, MD, PhD (D) \\ Complexo Hospitalario Universitario A Coruna, Breast Unit, A Coruña, Spain
}

Indication for chemotherapy as initial treatment for early breast cancer has modified its surgical treatment, allowing breast preservation in most patients who develop clinical response. ${ }^{1}$ However, in spite of high rates of pathologic complete response (pCR) in the axilla (26-66\%), in particular in patients with human epidermal growth factor receptor 2 (HER2) + and triple-negative tumor subtypes, there is still controversy about deescalation in surgical treatment of the axilla for patients with metastatic lymph nodes at diagnosis $(\mathrm{pN}+)^{2}$

Our recent paper $^{3}$ proves that it is feasible to identify and remove the metastatic lymph nodes marked with the clip/wire $(100 \%)$, and in most patients $(80 \%)$, this matched the sentinel lymph node (SLN). Also, in $90 \%$ of the patients with persistent lymph node disease, the marked lymph node was able to identify the residual disease.

However, no consensus on the gold-standard method for postchemotherapy axillary staging for $\mathrm{pN}+$ women has been reached to date. Yet, the reality is that, if we accept the definition of the SLN as the node with greater likelihood of being affected by the disease, we should recognize that, for women with metastatic involvement of the axilla, the disease itself marks its SLN. ${ }^{4}$ Therefore, once the SLN has been identified (the one selected for the disease), the important thing is to discover the axillary type of therapeutic response to chemotherapy. Removal of the marked metastasized lymph node should predict residual disease, which would make

(C) Society of Surgical Oncology 2020

First Received: 19 July 2020

Accepted: 22 July 2020;

Published Online: 3 August 2020

A. García-Novoa, MD, PhD

e-mail: mag_1406@hotmail.com marking the SLN unnecessary. This theory is similar to the paradox of the Theseus ship. Although all its original pieces have been replaced by new ones, the boat is still the same. Likewise, the SLN chosen by disease undergoes changes due to chemotherapy, but it is still the SLN, even though another marker (such Tc99 or patent blue) indicates a different SLN.

We should change our mind and not think of postchemotherapy axillary study as a restaging or "new boat" but rather as a tool to decide the rest of the adjuvant treatments. Most patients undergoing neoadjuvant chemotherapy (NAC) are HER2 + or have triple-negative tumor subtypes, with a high probability of pCR in the axilla, where axillary treatments might be unnecessary.

DISCLOSURES The authors declare no conflicts of interest.

\section{REFERENCES}

1. Rastogi P, Anderson SJ, Bear HD, Geer CE, Kahlenberg MS, Robidoux A, et al. Preoperative chemotherapy: updates of National Surgical Adjuvant Breast and Bowel Project Protocols B-18 and B-27. J Clin Oncol. 2008; 26(5):778-85. https://doi.org/10.1200/jco.2007.15.0235.

2. Simons JM, van Nijnatten TJA, van der Pol CC, Luiten EJT, Koppert LB, Smidt ML. Diagnostic accuracy of different surgical procedures for axillary staging after neoadjuvant systemic therapy in node-positive breast cancer: a systematic review and metaanalysis. Ann Surg. 2019 Mar;269(3):432-442.

3. García-Novoa A, Acea-Nebril B, Díaz Carballada C, et al. Combining wire localization of clipped nodes with sentinel lymph node biopsy after neoadjuvant chemotherapy in node-positive breast cancer: preliminary results from a prospective study. Ann Surg Oncol. (2020). https://doi.org/10.1245/s10434-020-08925-5.

4. Tanis PJ, Nieweg OE, Valdés Olmos RA, Th Rutgers EJ, Kroon BB. History of sentinel node and validation of the technique. Breast Cancer Res. 2001;3(2):109-12.

Publisher's Note Springer Nature remains neutral with regard to jurisdictional claims in published maps and institutional affiliations. 